http://dx.doi.org/10.18675/1981-8106.vol26.n51.p03-18

\title{
Cultura digital e Educação Física: problematizando a inserção de Exergames no currículo
}

\author{
Digital Culture and Physical Education: \\ questioning the inclusion of Exergames in the curriculum
}

Cultura digital y Educación Física:

problematizando la inserción de Exergames en el currículo

\begin{abstract}
César Augusto Otero Vaghetti ${ }^{1}$
Karina Langone Vieira"

Silvia Silva da Costa Botelho "II

'Exergame Lab Brazil - Universidade Federal de Pelotas (UFPEL), Escola Superior de Educação

Física - ESEF, Rio Grande do Sul - Brasil. E-mail: cesarvaghetti@gmail.com

"C3 - Centro de Ciências Computacionais/ NAUTEC - Universidade Federal do Rio Grande (FURG), Rio Grande do Sul - Brasil. E-mail: karinavieira_35@hotmail.com

III C3 - Centro de Ciências Computacionais/ NAUTEC - Universidade Federal do Rio Grande (FURG), Rio Grande do Sul - Brasil. E-mail: silviacb@furg.br
\end{abstract}

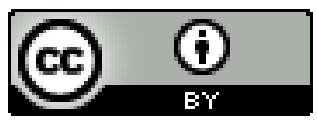

Educação: teoria e prática, Rio Claro, SP, Brasil - eISSN: 1981-8106

Está licenciada sob Licença Creative Common

\section{Resumo}

Os jogos são conhecidos por serem utilizados na educação, como ferramentas pedagógicas, porque eles podem facilitar a aprendizagem cognitiva. Diversas áreas, como Matemática, Geografia, História, Química e Biologia usam essa tecnologia em razão do seu potencial ilustrativo sobre o conteúdo a ser trabalhado, algo que muitos jogos possuem. Além disso, um dos aspectos mais importantes a serem considerados é a comunicação estabelecida entre educador e educando, em que o prazer e entretenimento são características inerentes ao jogo, agradando assim o aluno e permitindo o aprendizado. Atualmente, uma nova classe de jogos 
está tomando a atenção de crianças, jovens e adultos: os Exergames ou Interfaces Esforço, que misturam jogo e exercício físico. Não apenas como novas ferramentas educacionais, torna-se indispensável atenção em relação aos aspectos fisiológicos e educacional para o desenvolvimento humano, começa a ser exigido a partir de áreas como Ciências da Saúde, Educação, especialmente na Educação Física. Esta pesquisa teve como objetivo discutir, de forma crítica, questões relacionadas com as Exergames e a possibilidade de que eles sejam incluídos no currículo de Educação Física, na escola e nos cursos de graduação e pósgraduação.

Palavras-chave: Exergame, Educação Física, Currículo.

\begin{abstract}
Games are known to be used in education, as teaching tools, because they can facilitate cognitive learning. Several areas such as Mathematics, Geography, History, Chemistry and Biology use this technology in reason of its illustrative potential on the content to be worked, something that many games make possible. Moreover, one of the most important aspects to be considered is the communication established between educator and learner, in which pleasure and entertainment are inherent features of the game, thus pleasing the student and enabling learning. Currently, a new class of games is taking the attention of children, young people and adults: the Exergames or Exertion Interfaces, which mix game and physical exercise. Not only as new educational tools that become available but also some attention concerning physiological and educational aspects for the human development begin to be demanded from areas like Health Sciences, especially Physical Education. This research aimed at discussing, in a critical way, issues related to the Exergames and the possibility for them to be included in the curriculum of Physical Education, both at school and in the undergraduate and graduate courses.
\end{abstract}

Keywords: Exergame, Physical Education, Curriculum.

\title{
Resumen
}

Los juegos son conocidos por ser utilizados en la educación como herramientas pedagógicas, porque estos pueden facilitar el aprendizaje cognitivo. Diversas áreas como Matemáticas, Geografía, Historia, Química y Biología utilizan esta tecnología en razón de su potencial ilustrativo sobre el contenido a ser trabajado, algo que muchos juegos poseen. Además, uno de los aspectos más importantes a ser considerado es la comunicación establecida entre educador y educando, en la que el placer y el entretenimiento son características inherentes al juego, agradando así al alumno y permitiendo el aprendizaje. Actualmente, una nueva 
clase de juegos está llamando la atención de niños, jóvenes y adultos: los Exergames o Interfaces Esfuerzo, que mezcla juego y ejercicio físico. No apenas como nueva herramienta educacional, los Exergames se han vuelto indispensables en la atención a los aspectos fisiológico y educacional para el desarrollo humano, que comienza a exigirse en áreas como las Ciencias de la Salud, Educación y, especialmente, en la Educación Física. Esta investigación tuvo como meta discutir, de forma crítica, cuestiones relacionadas con los Exergames y la posibilidad de que estos sean incluidos en el currículo de Educación Física, en la escuela y en los cursos de graduación y posgrado.

Palabras clave: Exergame, Educación Física, currículo.

\section{Introdução}

Estamos vivendo num tempo em que os avanços tecnológicos alteram os hábitos cotidianos, instituindo novos modos de interações, mediados pelas tecnologias. A velocidade do surgimento de dispositivos tecnológicos cria necessidades e institui diferentes modos de interação.

Pode-se mesmo afirmar que as tecnologias ditam a velocidade da sociedade. (GUILLAUME, 2004). As mídias, a internet, os processadores mais velozes, computadores com novas interfaces partilham um horizonte comum, globalizado. Há uma quase infinidade de informações disponíveis hoje na web, mediante um breve toque no teclado; entretanto, nem toda essa disponibilidade pode ser utilizada. Ambientes Virtuais de Aprendizagens (AVA) estão sendo utilizados por instituições educativas, como é o caso também das Tecnologias da Informação e Comunicação (TIC), presentes cada vez mais em salas de aula e no nosso dia a dia.

Silveira e Torres (2007) investigaram os jogos eletrônicos na Educação Física escolar e os resultados da pesquisa indicam a necessidade de as escolas refletirem sobre a seleção dos jogos eletrônicos como conteúdo, oferecendo possibilidades de educar os jovens para a cultura eletrônica que, como outras formas culturais, interfere na capacidade dos sujeitos perceberem a realidade. Os pesquisadores afirmam que o futebol já não é mais só uma "pelada" num terreno baldio; é também videogame, jogos em computador, espetáculo da TV.

Alguns artefatos tecnológicos, como a fotografia analógica e a digital, os filmes, a televisão, o computador e o videogame são recursos tecnológicos desenvolvidos com diferentes finalidades e que, com o passar dos anos, sofreram aprimoramentos e mais intensamente contribuem para constituir o que chamamos hoje de cultura digital. A fotografia, os filmes e a televisão foram os precursores das ditas "novas tecnologias" com as quais tivemos contato. É possível pensar que elas tornaram-se responsáveis por povoar nosso 
cérebro com imagens, movimentos e sons, trazendo ao nosso dia a dia um novo modo de apreender o mundo.

O computador que, por sua vez, começou a ser desenvolvido em 1946, tornou-se hoje peça indispensável a qualquer setor da sociedade: através da web, milhões de pessoas têm acesso à informação, à educação e à diversão. As redes sociais de relacionamento, com as quais também aprendemos a conviver, (como Orkut, Facebook, Myspace, Sonico, e outros tipos de redes como blogs) configuram um modo de interação caracterizado pela partilha de informações e conhecimentos até então inexistente entre os humanos. Por esse extenso uso da tecnologia, os efeitos das mudanças decorrentes dos avanços no setor estão sendo cada dia mais percebidos na sociedade contemporânea.

Os videogames surgem no final da década de 1970, propondo uma nova possibilidade de interação homem-máquina. Inicialmente, o hábito de jogar e de interagir com os jogos eletrônicos era através do fliperama, onde havia os grandes jogos eletrônicos do tipo arcade e as máquinas de pinball, que misturavam destreza manual e sorte, e que existem até hoje. Anos mais tarde, nomes como Atari, Odissey, Intellivision surgem para fixar de vez a cultura dos jogos eletrônicos como prática de lazer.

Recentemente, em 2006, foi desenvolvido o Nintendo Wii Sports, possibilitando ao usuário ter a experiência concreta do movimento de diversos esportes, como golf, boxe, tênis, boliche, baseball, arco e flecha. Isso sem falar no Wii Fit, que permite praticar yoga, skate e snowboard. Esse game utiliza acelerômetros dentro dos controles (wii remote) para mensurar os movimentos da mão do usuário em três dimensões, ampliando as possibilidades de interação humana e imersão em um game. (FITZ-WALTER et al., 2008).

Conforme afirmam Sinclair et al. (2007) este tipo de jogo é conhecido na literatura como Exergames, pois mistura exercício físico com game, permitindo que a fascinação pelos games seja tão aproveitada quanto a prática do exercício físico. Um Exergame de grande sucesso foi o Dance Dance Revolution (DDR), criado em 1998 e que, segundo Hämäläinen et al. (2005) sua fórmula "mágica" inclui nada mais que dança, game e música. Outros games como Eye Toy, do Play Station, também permitem essa interação e, portanto, podem ser classificados como Exergames.

Somado a isso, os Exergames são uma nova ferramenta educacional principalmente para as Ciências da Saúde, podendo ser utilizados como AVAs na Educação Física, Medicina, Fisioterapia, Psicologia e tantas outras áreas que se envolvem com processos de formação, isso porque o movimento humano é característica fundamental nesses tipos de games.

Alguns autores, como Parizkova e Chin (2003) e Sothern (2004), destacam vários aspectos educacionais nos games, contudo, classificam os games tradicionais como atividades sedentárias. Em comparação com os Exergames, o aspecto lúdico do jogo e a fascinação da realidade virtual estão contribuindo para o crescente sucesso de tais jogos. A possibilidade de 
utilizar o movimento humano como parte integrante do jogo cria um ambiente favorável para o processo de ensino-aprendizagem, estabelecendo-se como potencial ferramenta didáticopedagógica a ser utilizada nas instituições educativas, nas clínicas de reabilitação, nas intervenções psicopedagógicas. Podem também se tornar um objeto de investigação por parte da comunidade científica. (PAPASTERGIOU, 2009). Deste modo, não apenas novas ferramentas pedagógicas se tornam disponíveis, como também é exigida de áreas como as Ciências da Saúde, especialmente a Educação Física, uma atenção voltada aos aspectos fisiológicos e educacionais do movimento humano.

Neste ínterim de transformações pela tecnologia, a cultura deixa de ser entendida como apenas experiências, crenças, valores e tradições, e passa a ser tratada como campo de batalhas, de contestação e de invenção de conhecimentos nos quais as comunidades são constituídas por constantes processos de mudanças. Na perspectiva de Turkle (1997) a cultura da simulação emerge diante dos modelos computacionais como sendo estes os seus representantes e dos jogos eletrônicos como elementos que compõem tais representações. Estas são instauradoras de uma lógica não linear e fazem parte do universo da geração Screenagers.

Rushkoff (1999) utiliza a expressão Screenagers quando se refere à geração nascida a partir da década de oitenta, pós-controle remoto, joystick, mouse e recursos que buscam a interação com os jogos eletrônicos mais recentes, exigindo rapidez de movimentos e demandando uma inteligência sensório-motora, o que ratifica a ideia de essas gerações apresentarem formas distintas de pensar e compreender o mundo, de percorrer novas trilhas, de participar de metamorfoses virtuais, de escolher diferentes personagens ou avatares, de inventar outra forma de ser e estar no mundo, experimentando um tornar-se diferente de si mesmo e que ocorre com o desenvolvimento da tecnologia. Neste sentido, o objetivo desta pesquisa foi problematizar a inserção dos jogos eletrônicos, games, principalmente os Exergames, nos currículos dos cursos de Educação Física - Licenciatura e Bacharelado - e Educação Física Escolar.

\section{Games: diversão, prazer, ferramenta pedagógica}

Mas o que há de realmente divertido no jogo? Por que há uma espécie de hipnose? Uma euforia que busca a realização de um desejo incontrolável na qual o tempo "parece congelar" e o que prevalece é a busca do prazer? Por que motivo o jogador se deixa absorver inteiramente por sua paixão? Por que uma multidão imensa pode ser levada ao delírio por um jogo de futebol? Essas inquietações, de Huizinga (2005) permitem-nos entender que tal intensidade, verdadeira fascinação pelo jogo e para o jogo, é onde reside a própria essência do jogo. $\mathrm{O}$ autor relata que a natureza poderia nos ter oferecido inúmeras funções de descarga de energia excessiva, de preparação para as exigências da vida, de compensação de desejos 
insatisfeitos, mas ela nos deu a alegria, o prazer e entretenimento, contemplados na prática do jogo.

Sendo assim, podemos dizer que o jogo faz parte da sociabilidade humana de maneira lúdica, alegre e prazerosa. O jogo habita a vida de diferentes instituições educativas formais e informais. Porém, a escola, tal como é conhecida hoje, nasce na modernidade, com uma proposta moralizadora de enclausurar os escolares e é justamente a partir daí, de modo contraditório, que muitos avanços são possíveis em termos pedagógicos. Entretanto, alguns desses avanços parecem não ter se efetivado na prática. A descoberta, por exemplo, por parte dos educadores, de que o prazer é fundamental para o processo de ensino e aprendizagem tem eco em diversas teorias, mas tem ressonância no cotidiano das escolas?

Os jogos eletrônicos apresentam todas as vicissitudes para efetivar processos de atualização. Ou seja, conseguem inventar caminhos e cenários inexistentes, nos quais o jogador utiliza os conteúdos que impulsionam a construção de narrativas sem predefinição, uma vez que potencializam a imersão em um universo de histórias onde o player ocupa o papel de interator. (ALVES e HETKOWSKI, 2007).

Sendo assim, tudo aquilo que desperta a curiosidade e a atenção do jovem pode ser fonte e recurso para a escola aproveitar como meio educativo. Isso porque o prazer e a curiosidade fomentam o aprendizado, podendo romper as limitações do próprio modelo de escola que existe hoje. (RIBEIRO, 2010). Educadores como Lopes (1998) e Maciel (2001) trouxeram a influência psicanalítica e passaram a propor que os processos de ensino e aprendizagem fossem vistos a partir da ideia de desejo. Em outras palavras, seria imprescindível o desejo para que a criança pudesse verdadeiramente aprender. Enfim, os jogos eletrônicos de diferentes narrativas e conteúdos, segundo Alves (2000), atuam na Zona de Desenvolvimento Proximal dos sujeitos, de forma lúdica, prazerosa e atrativa.

Os elementos do jogo eletrônico são chamados de elementos do game play. Vannucchi (2010) afirma que, embora definido por regras e pela mecânica do jogo, existem elementos presentes nos games - o lúdico, a jogabilidade, a narrativa, a interface, a imersão, entre outros que colaboram para a fantasia e simulação dos jogos da era digital. O aspecto importante dessas considerações é que os elementos contribuem e interferem na diversão do jogador, no prazer do usuário em jogar um game.

Sobre a imaginação, a representação, os inúmeros devires que podem ser pensados a partir do jogo, Huizinga (2005) relata:

Seja como for, para o indivíduo adulto e responsável, o jogo é uma função, que facilmente poderia ser dispensada, é algo supérfluo. Só se torna uma necessidade urgente na medida em que o prazer por ele provocado transforma-o numa necessidade. É possível, em qualquer momento, adiar ou suspender o jogo. Jamais é imposto pela necessidade física ou pelo dever 
moral. A criança representa alguma coisa diferente: ou mais bela, ou mais nobre, ou mais perigosa do que habitualmente é. Finge ser um príncipe, um papai, uma bruxa malvada ou um tigre. A criança fica literalmente "transportada" de prazer, superando-se a si mesma, a tal ponto, que quase chega a acreditar que realmente é esta ou aquela coisa, sem, contudo, perder inteiramente o sentido da "realidade habitual". Mais do que uma realidade falsa, sua representação é a realização de uma aparência: é "imaginação", no sentido original do termo. (HUIZINGA, 2005, p. 10)

Nessa perspectiva, não é novidade falar da necessidade de a escola facilitar processos nos quais o estudante possa ter prazer em estudar, em estar na escola e em aprender. Apesar das inúmeras discussões que permeiam a questão do prazer e da escola, como as relacionadas às teorias da motivação interna e externa, às teorias instrucionistas e do inconsciente, parece ser um assunto digno de atualização, sobretudo quando inserido no contexto escolar, no currículo, elementos de grande poder de interação e sedução como o videogame.

Levar o jogo digital, eletrônico, para o cenário escolar não significa pensar nesse artefato cultural para desenvolver os conceitos de matemática; ou para a aprendizagem da língua; ou para os processos cognitivos: esta compreensão das tecnologias, das mídias digitais e suas representações é reducionista, contrária às perspectivas teóricas que discutem a presença desses elementos nos ambientes de aprendizagem, principalmente nos escolares. Contrapõe-se também às clássicas teorias psicogenéticas dos autores Piaget, Vygotsky, Wallon, entre outros, existentes há mais de cinquenta anos e são exaustivamente discutidas nos cursos de formação de professores. Quanto ainda precisamos caminhar para compreender que o lúdico deve estar presente nas situações de aprendizagem? E que a escola deve se constituir em um espaço de prazer?

\section{Games no currículo da Educação Física}

A problematização do jogo como manifestação cultural prestigiada no currículo da Educação Física exige a consideração de um novo entendimento do papel do mesmo na escola. Segundo Neira (2009), em lugar de pensá-lo como conteúdo que regula e controla os alunos, a concepção aqui adotada propõe uma abordagem histórico-cultural do jogo, ou seja, concebe-o como artefato cultural pertencente ao homem histórico.

O currículo é definitivamente um espaço de poder; o conhecimento corporificado no currículo segundo Silva (2000) carrega as marcas indeléveis das relações sociais de poder. O currículo é capitalista, reproduz culturalmente as estruturas sociais das classes da sociedade capitalista, transmite a ideologia dominante, em suma, é um território político. A invenção e a propagação do currículo estão relacionadas às mudanças que ocorreram na Europa pós- 
renascentista, com as formas de pensar vigentes à época. Então, o currículo, assim como a escola, é fruto da era moderna.

Entretanto, conforme Veiga-Neto (2002) a geometria agora é outra: o autor chama a atenção para a ruptura da espacialidade moderna na direção da pós-moderna, a dissolução das fronteiras, a volatilidade e a globalização, uma nova ordem epistemológica em que estamos mergulhados e que, consequentemente, traz implicações para o currículo. Em outras palavras, vivemos num mundo pós-moderno, se assim podemos chamá-lo; vivemos num mundo completamente diferente daquele do século passado, no qual o jovem chega à escola trazendo na bagagem toda uma cultura digital. Imerso em redes de relacionamentos sociais digitais, o jovem do século XXI participa ativamente da construção da chamada inteligência coletiva (Lévy, 1999a) e encontra na escola do século XX uma barreira, uma contraposição ao seu mundo; uma escola que não reconhece a educação como ubíqua, tampouco suas diferentes formas tecnológicas atuais.

Reis e Cavichiolli (2008) estudaram a presença dos jogos eletrônicos como opção de lazer na vida moderna, visto que o lazer é uma área de grande interesse para a Educação Física. Os pesquisadores afirmam que os games de última geração, os Exergames, mudaram completamente o contexto do mundo dos games. Neles, o usuário realiza movimentos com o corpo inteiro, simulando técnicas esportivas e, em razão disso, a nova maneira de jogar poderá influenciar diretamente a prática esportiva e a Educação Física.

Como, então, produzir heterotopias no espaço escolar? O questionamento de Gallo (2007) sobre como alterar a configuração do currículo planificado, organizado, disciplinado, implica o modo de como ir além dessa geometria curricular; nas palavras de Deleuze (1992), o modo de como engendrar novo espaço-tempo que institua relações pedagógicas diferenciadas. Já para Foucault (2001):

Há igualmente, e isso provavelmente em qualquer cultura, em qualquer civilização, lugares reais, lugares efetivos, lugares que são delineados na própria instituição da sociedade, e que são espécies de contra posicionamentos, espécies de utopias efetivamente realizadas nas quais os posicionamentos reais, todos os outros posicionamentos reais que se podem encontrar no interior da cultura estão ao mesmo tempo representados, contestados e invertidos, espécies de lugares que estão fora de todos os lugares, embora eles sejam efetivamente localizáveis. Esses lugares, por serem absolutamente diferentes de todos os posicionamentos que eles refletem e dos quais falam, eu os chamarei, em oposição às utopias, de heterotopias. (FOUCAULT, 1999, p. 415).

De acordo com o ponto de vista dos pesquisadores citados, podemos então classificar os games como heterotopias, pois é possível passar horas em um jogo, eletrônico ou não, um game, no qual o jogador, o usuário, o gamer pode facilmente ser levado para um lugar 
qualquer, um lugar digital, um lugar imaginável, um lugar irreal, um lugar de infinitas possibilidades, um lugar de diversas redes de ensino e aprendizagem. Segundo teorias póscríticas, o currículo está irremediavelmente envolvido nos processos de formação pelos quais nos tornamos o que somos, ao contrário das teorias tradicionais, em que a preocupação gira em torno das melhores e mais eficientes formas de organizar o currículo.

O computador não apenas parece capaz de realizar ações humanas, como também toda a atividade mediada por ele pressupõe o desenvolvimento de capacidades cognitivas e metacognitivas. Sancho (2006) afirma que a exploração da informação em qualquer área do currículo escolar melhora imediatamente a motivação, o rendimento e as capacidades cognitivas dos alunos. Cinema, computador, televisão, videogames atraem de forma especial a atenção dos mais jovens, que desenvolvem grande habilidade para captar as mensagens desses meios, tornando-os ferramentas poderosas para o ensino.

Especialmente no âmbito da Educação Física, Silveira e Torres (2007) discorrem sobre a existência do currículo vazio, citado por Cherryholmes (1993), o qual se constitui nos conhecimentos ausentes, tanto do ponto de vista da proposta curricular formal, quanto das práticas da sala de aula e que, muitas vezes, abrangem conhecimentos significativos e até mesmo fundamentais para a compreensão da realidade e para a atuação nela. Games como o FIFA World Cup (PS3) e a maioria dos jogos de esportes do Nintendo Wii, configuram os grandes temas da Educação Física que, segundo Bracht (1999), são os jogos, as danças, as lutas, os esportes e as ginásticas. Sendo assim, então, por que não utilizar games e Exergames nas disciplinas que trabalham com os referidos temas nas aulas?

Os cursos de Educação Física deverão, o quanto antes, rever seu currículo, caso contrário correrão o risco de apresentar conteúdo defasado e desconectado da realidade, tanto nas licenciaturas, que focam a educação corporal, cultura corporal e a aprendizagem motora, quanto nos bacharelados, cujo foco se dirige para a performance e a técnica.

Em uma pesquisa recente sobre a utilização dos EXG na Educação Física, Vaghetti e Botelho (2010) investigaram diferentes Exergames existentes no mercado e suas implicações pedagógicas. Os pesquisadores concluíram que sua utilização ainda está relacionada ao entretenimento e às formas alternativas de exercício físico e sua inclusão no ambiente escolar limita-se à capacitação dos professores. Kirriemuir e McFarlane (2004) também destacam que os professores sentem dificuldades em identificar se o conteúdo de um jogo é relevante ou não para um determinado tema tratado no currículo escolar. Além disso, a falta de tempo para se familiarizar com a tecnologia também constitui um entrave para esses professores incluíremna em seus planejamentos de aula.

Em estudo realizado em 20 escolas da Virgínia Ocidental (EUA) sobre a utilização do Exergame Dance Dance Revolution (DDR) em aulas de educação física e saúde, Liberman (2006) afirma que alguns jovens perderam cerca de $4 \mathrm{~kg}$ após fazer uso dele na escola. Com 
base nos resultados positivos levantados pelo estudo mencionado, aquele estado está implementando no currículo da Educação Física escolar o uso do DDR em todas as suas 765 escolas públicas. Além de ferramenta contra obesidade infantil, o game em questão é uma excelente ferramenta para trabalhar habilidades motoras e cognitivas. Além dos aspectos citados, professores relatam que uma única unidade do DDR em sala de aula pode beneficiar toda a classe. Com ela, as crianças que não estão jogando podem assistir ao colega jogar e podem, ao mesmo tempo, ensaiar as suas jogadas.

\section{Games e Exergames na Educação Física}

Quais os impactos para a Educação Física trazidos pelo advento dos Exergames? O que poderá ser transformado em termos de processos pedagógicos e método de ensino e aprendizagem? Que estruturas cognitivas serão construídas na sua utilização?

Os seres humanos, segundo Lévy (1999b), retêm melhor as informações quando elas estão relacionadas com situações ou domínios de conhecimento que lhes sejam familiares. Nesse sentido, os Exergames representam um ambiente no qual o usuário pode praticar um esporte e interagir em um game ao mesmo tempo, ou seja, a possibilidade de um game e de um exercício em um mesmo ambiente. Para o autor em questão, assistimos à desterritorialização da biblioteca através das tecnologias digitais, mas esse processo tem seus aspectos positivos: aumentou o fluxo de informações, especialmente com a Internet, permitindo maior acesso a essa informação e tornou a educação realmente ubíqua.

Do mesmo modo um Exergame pode promover esse deslocamento de lugar, com o usuário podendo facilmente ser transportado para um lugar qualquer: digital, imaginável, irreal. Enfim, um lugar de infinitas possibilidades e de finitas redes de ensino e aprendizagem.

Em atividades de lazer, os indivíduos procuram a excitação; procuram experimentar emoções que, frequentemente, não estão presentes em sua vida cotidiana ou, caso estejam, não oferecem um nível elevado satisfatório de tensão-excitação. Ao contrário do que se costuma afirmar, os indivíduos não procuram atividades de lazer para extravasarem suas tensões ou atenuarem as cargas emocionais adquiridas, mas para elevar os níveis de tensão, colocar-se em situações excitantes, vivenciar momentos que incitem ou favoreçam o desabrochar de emoções variadas. (REIS E CAVICHIOLLI, 2008). Portanto, é a excitação, e não o relaxamento que constitui o elemento principal em grande parte das atividades de lazer. Logo, por que não transformar o processo ensino-aprendizagem em lazer?

A excitação é um dos elementos presentes no jogo, com capacidade de estabelecer uma conexão favorável na criação de um ambiente virtual de aprendizagem, em que a realidade virtual dos games é a tecnologia capaz de produzir essa excitação. O termo jogabilidade ou jogability, segundo Pasch et al. (2009), significa a capacidade do game de 
atrair a atenção do usuário; portanto, aspectos como interatividade, imersão, fantasia, enredo e desafio são elementos dos jogos eletrônicos por meio dos quais as conexões com o usuário são estabelecidas. A interatividade se relaciona com a capacidade do usuário de interagir com a tecnologia do game: saber jogar e utilizar os recursos do jogo e as ferramentas oferecidas é a usabilidade de software, ou seja, ergonomia cognitiva. A imersão é a capacidade do game de levar o usuário para o mundo virtual; é o poder da tecnologia virtual, criando a sensação de pertencimento ao mundo virtual, ao mundo da fantasia.

O enredo é a narrativa do game, é o objetivo e as metas do usuário dentro do ambiente virtual: resgatar a princesa, fazer mais pontos, vencer o adversário em um esporte; nele também estão colocados os desafios do jogo. No caso dos Exergames, as narrativas estão relacionadas ao grau de habilidade motora e nível de esforço físico requerido para a realização de determinada tarefa. Para avançar de fase ou vencer novos adversários, não bastam habilidades cognitivas e habilidade motora nos dedos para a manipulação do joystick, mas também esforço físico e coordenação de membros superiores e/ou inferiores. Epstein et al. (2007) investigaram a interatividade em 35 crianças entre oito e doze anos, para as quais um Exergame, que utiliza dança, música e o próprio jogo DDR foi mais motivador do que a execução de movimentos de dança realizada quando estão sozinhas ou assistindo à televisão. Resultados semelhantes também foram encontrados por Marijke et al. (2008), que investigaram 27 crianças em escolas primárias, acerca do uso do IDSVG (Interactive Dance Simulation Videogame) e verificaram que os games multiplayer também aumentam a motivação. De forma análoga ao pensamento sistêmico, conhecer as partes, ou seja, os elementos do jogo e sua adequação às faixas etárias e aos níveis intelectuais dos alunos, não é suficiente para compreender os processos de ensino e aprendizagem. Antes, é necessário compreender o aluno e suas relações com as ferramentas pedagógicas, nos diferentes ambientes e contextos.

Games como FIFA World Cup (futebol), Fight Night Round 4 (Boxe), Madden NFL 2010 (Futebol Americano) ou NBA 08 (Basquete) podem ser ferramentas para estudar em sala de aula aspectos técnicos, processos pedagógicos, regras, táticas, preparação desportiva e aprendizagem motora nos esportes citados. Da mesma forma, Exergames como o Nintendo Wii possuem diversos games através dos quais os temas da Educação Física podem ser trabalhados. No esporte, games como baseball, golf, boliche, arco e flecha, tênis, tênis de mesa, basquete, hockey, snowboard e canoagem podem ser utilizados nas diversas disciplinas dentro de um currículo de Educação Física. Na fisiologia do exercício, por exemplo, o esforço físico e o gasto calórico da canoagem e do boxe podem ser estudados; na aprendizagem motora, as habilidades com o arco e a flecha permitem demonstrar ao aluno as dificuldades dos esportes de tiro; no golf, além da motricidade, podem ser trabalhadas noções de centro de gravidade, variável fundamental para o entendimento do movimento humano em disciplinas como biomecânica e cinesiologia. 
Na ginástica, o Wii Fit permite realizar movimentos de yoga em uma plataforma que mensura, além da massa corporal, a distribuição do peso na área da base de sustentação. $\mathrm{Na}$ dança, o Dancing Wii possibilita recriar o DDR, já citado anteriormente, e é um dos games de maior gasto calórico. (TAN et al., 2002). Além dos games já mencionados, o Guitar Hero, uma simulação de acordes de guitarra, possibilita trabalhar a motricidade motora fina.

\section{Considerações Finais}

Os Exergames devem ser vistos não apenas como uma ferramenta pedagógica no currículo da Educação Física, mas como uma possibilidade de direcionar para o surgimento de novos modos de cognição e de percepção. Não devem ser considerados como ferramenta migrante do espaço virtual para o físico presencial, mas como algo que vem estabelecendo novas conexões de aprendizagens e sociabilidades nas instituições educativas.

Sendo assim, os Exergames, ao quebrarem os "muros" que separam as aprendizagens do físico presencial das do virtual, tendem a favorecer o surgimento de outro papel para o professor de Educação Física. Emerge, assim, um professor mediador, que se utiliza dessas ferramentas de acordo com as temáticas a serem trabalhadas nas aulas de Educação Física. Para que isso aconteça, esse professor deve saber utilizar as tecnologias em seu dia a dia, a fim de incorporá-las no cotidiano escolar. Isso passa pela formação continuada, pois não são os instrumentos que mudam as práticas docentes profundamente enraizadas, mas, ao contrário, tais práticas transformam as tecnologias em ferramentas pedagógicas.

É possível afirmar que, se os Exergames forem incorporados às práticas da Educação Física, os currículos escolares sofrerão alterações significativas. As considerações aqui mencionadas causam algum receio? Acredita-se que sim, pois nos slogans fixados no currículo escolar, prevalecem a repetição e a memorização, que impossibilitam o movimento corporal em sala de aula. São juízos, comportamentos, interesses político-sociais e econômicos do passado e da modernidade, que ainda estão em vigência como crenças cultivadas.

Por outro lado, os Exergames emergem como possível ferramenta e recursos necessários à facilitação de novas intervenções na escola, as quais resultam em outras formas de relações de ensino e de aprendizagem, oportunizadas pela Educação Física.

Neste sentido é um desafio interessante, para a educação, conhecer o modo como operam as ferramentas tecnológicas contemporâneas, uma vez que elas revelam as formas sociais que as produzem e lhes dão sentido, instituindo redes de interações interpessoais, modos de pensamentos e linguagens próprias. 


\section{Referências}

ALVES, L.R.G. Conhecimento e Internet: uma construção possível? Revista da Faculdade de Educação, n.1, [s.1.], [s.n.], 2000, p. 91-108.

ALVES, L. R. G.; HETKOWSKI, T. M. Gamers brasileiros. Quem são e como jogam? In: NASCIMENTO, A. D.; FIALHO, N. H.; HETKOWSKI, T. M.; [Org.]. Desenvolvimento sustentável e tecnologias da informação e comunicação. Salvador: EDUFBA, 2007, p. 161174.

BRACHT, V. A constituição das teorias pedagógicas da Educação Física. Cadernos Cedes. n. 48, [s.1.], [s.n.], p. 69-88, 1999.

CHERRYHOLMES, C. H. Um projeto social para o currículo: perspectivas pós-estruturais. In: SILVA, T. T. da. [Org.]. Teoria educacional crítica em tempos pós-modernos. Porto Alegre: Artes Médicas, 1993, p. 143-172.

DELEUZE, G. Post-Scriptum sobre as sociedades de controle. Rio de Janeiro: Editora 34, 1992.

<http://www.portalgens.com.br/filosofia/textos/sociedades_de_controle_deleuze.pdf > Acesso em: 15 set. 2013.

EPSTEIN, L. H.; BEECHER, M. D.; GRAF, J. L.; ROEMMICH, J. N. Choice of interactive dance and bicycle games in overweight and non overweight youth. Annals of Behavioral Medicine. n. 33, [s.1.], [s.n.], 2007, p. 124-131.

FRITZ-WALTER, Z.; JONES, S.; TJONDRONEGORO, D. Detecting gesture force peaks for intuitive interaction. In: Proceedings of the 5th Australasian Conference on Interactive Entertainment. December 3-4, Brisbane, Australia, 2008, 475-483.

FOUCAULT, M. Ditos e escritos. Rio de Janeiro: Forense Universitária, v. 5, 1999.

GALLO, S. Educação menor: produção de heterotopias no espaço escolar. In: RIBEIRO, P. R. C. et al. [Org.]. Corpo, gênero e sexualidade: discutindo práticas educativas. Rio Grande: Editora da FURG, 2007.

GUILlAUME, M. A revolução comutativa. In: PARENTE, A. [Org.] Tramas da rede: novas dimensões filosóficas, estéticas e políticas da comunicação. Porto Alegre: Sulina, 2004. 
HÄMÄLÄINEN, P.; ILMONEN, T.; HÖYSNIEMI, J.; LINDHOLM, M.; NYKÄNEN, A. Martial arts in artificial reality. In: Proceedings of the SIGCHI Conference on Human factors in computing systems. Portland: [s.n.], 2005, p. 781-790.

HUIZINGA, J. Homo Luddens: o jogo como elemento da cultura. 5 ed. São Paulo: Perspectiva, 2005.

KIRRIEMUIR, J.; MCFARLANE, A. Literature review in games and learning. Futurelab Series. n. 8. University Bristol: [s.n.], 2004, p. 1-39.

LÉVY, P. As tecnologias da inteligência: o futuro do pensamento na era da informática. Rio de Janeiro: Editora 34, 1999a.

LÉVY, P. Cibercultura. São Paulo: Editora 34, 1999 b.

LIEBERMAN, D. 2006. Dance games and other exergames: what the research says. Disponível em: <http://www.comm.ucsb.edu/faculty/lieberman/exergames.htm> Acesso em: 12 nov. 2015.

LOPES, E. M. T. A psicanálise escuta a educação. Belo Horizonte: Autêntica, 1998.

MACIEL, I. [Org.]. Psicologia e educação: novos caminhos para a formação. Rio de Janeiro: Ciência Moderna, 2001.

MARIJKE, J. M.; PAW, M. J. M. C. A.; JACOBS, W. M.; VAESSEN, E. P. G.; TITZE, S.; VAN MECHELEN, W. The motivation of children to play an active video game. Journal of Science and Medicine in Sport. n. 11, [s.1.], [s.n.], 2008, p. 163- 166.

NEIRA, M. G. Em defesa do jogo como conteúdo cultural do currículo da Educação Física. Revista Mackenzie de Educação Física. n. 8. São Paulo: [s.n.], 2009, p. 25-41.

PAPASTERGIOU, M. Digital Game-Based Learning in high school Computer Science education: impact on educational effectiveness and student motivation. Computers Education. n. 52. [s.1.], [s.n.], 2009, p. 1-12.

PARIZKOVA, J.; CHIN, M. Obesity prevention and health promotion during early periods of growth and development. Journal of Exercise Science and Fitness. n. 1. [s.1.], [s.n.], 2003, p. 1-14.

PASCH, M.; BIANCHI-BERTHOUZE, N.; DIJK, B. V; NIJHOLT, A. Movement-based sports video games: investigating motivation and gaming experience. Entertainment Computing. n. 1. [s.1.], [s.n.], 2009, p. 49-61. 
REIS, L. J. A.; CAVICHIOLLI, F. R. Jogos eletrônicos e a busca da excitação. Movimento. n. 14. [s.1.], [s.n.], 2008, p. 163-183.

RIBEIRO, M. A escola, o videogame e o prazer. In: VI SEMINÁRIO DE JOGOS ELETRÔNICOS, EDUCAÇÃO E COMUNICAÇÃO: CONSTRUINDO NOVAS TRILHAS. 2010. Universidade do Estado da Bahia: [s.n.], 2010, p. 1-9.

RUSHKOFF, D. Um jogo chamado futuro - Como a cultura dos garotos pode nos ensinar a sobreviver na era do caos. Rio de Janeiro: Revan, 1999.

SANCHO, J. M. De tecnologias da informação e comunicação a recursos educativos. In: SANCHO J. M., HERNÁNDEZ F. et al. Tecnologias para transformar a educação. Porto Alegre: Artmed, 2006.

SILVA, T. T. Documentos de identidade: Introdução às teorias do currículo. Belo Horizonte: Autêntica, 2000.

SILVEIRA, G. C. F.; TORRES, L. M. Z. B. Educação Física escolar: um olhar sobre os jogos eletrônicos. In: XV CONGRESSO BRASILEIRO DE CIÊNCIAS DO ESPORTE. [s.l.], [s.n.], 2007.

SINCLAIR, J.; HINGSTON, P.; MASEK, M. Considerations for the design of exergames. In: PROCEEDINGS OF THE 5TH INTERNATIONAL CONFERENCE ON COMPUTER GRAPHICS AND INTERACTIVE TECHNIQUES IN AUSTRALIA AND SOUTHEAST ASIA. 2007. [s.1.], [s.n.], 2007, p. 289-296.

SOTHERN, M. Obesity prevention in children: physical activity and nutrition. Nutrition. n. 20. [s.1.], [s.n.], 2004, p. 704-708.

TAN, B.; AZIZ, A.R.; CHUA, K.; THE, K.C. 2002. Aerobic demands of the dance simulation game. International Journal of Sports Medicine. n.23. [s.1.], [s.n.], 2002, p. 125-129.

TURKLE, S. A vida no ecrã - A identidade na era da Internet. Lisboa: Relógio d'Água, 1997.

VAGHETTI, C. A. O.; BOtELHO, S. S. C. Ambientes virtuais de aprendizagem na Educação Física: uma revisão sobre a utilização de Exergames. Ciências \& Cognição. n. 15. [s.n.], [s.1.], 2010, p. 76-88.

VANNUCCHI, H. Elementos do gameplay. In: VI SEMINÁRIO DE JOGOS ELETRÔNICOS, EDUCAÇÃO E COMUNICAÇÃO: CONSTRUINDO NOVAS TRILHAS. 2010. Universidade do Estado da Bahia, [s.n.], 2010, p. 1-10. 
VEIGA-NETO, A. De geometrias, currículo e diferenças. Educação \& Sociedade. n. 79. [s.1.], [s.n.], 2002, p. 163-186.

Recebido em: 14/10/2013

Revisado em: 18/04/2015

Aprovado para publicação em: 23/03/2016

Publicado em: 30/04/2016 